Article

\title{
Fluorescence Indices for the Proximal Sensing of Powdery Mildew, Nitrogen Supply and Water Deficit in Sugar Beet Leaves
}

\author{
Georg Leufen *, Georg Noga and Mauricio Hunsche \\ Department of Horticultural Sciences, Institute of Crop Science and Resource Conservation, \\ University of Bonn, Auf dem Huegel 6, Bonn D-53121, Germany; \\ E-Mails: nogag@uni-bonn.de (G.N.); MHunsche@uni-bonn.de (M.H.) \\ * Author to whom correspondence should be addressed; E-Mail: gleufen@uni-bonn.de; \\ Tel.: +49-228-73-6540; Fax: +49-228-73-5764.
}

Received: 15 January 2014; in revised form: 12 February 2014 / Accepted: 13 March 2014 / Published: 28 March 2014

\begin{abstract}
Using potted sugar beet plants we aimed to investigate the suitability of four fluorescence indices to detect and differentiate the impact of nitrogen supply, water deficit and powdery mildew in two sugar beet cultivars (Beta vulgaris L.). Plants were grown inside a polytunnel under two nitrogen levels combined with water deficit or full irrigation. Changes in plant physiology were recorded at two physiological stages with a multiparametric handheld fluorescence sensor and a fluorescence imaging system. The analysis of chlorophyll content and osmotic potential served as reference. Based on our results, the fluorescence indices "Nitrogen Balance Index" and "Simple Fluorescence Ratio" responded quite sensitively to drought stress and mildew infection. Moreover, the blue-to-far-red fluorescence ratio revealed significant stress-induced alterations in the plant physiology. In all, fluorescence indices might be used as single or combined indices for successful stress sensing. However, a robust stress differentiation by using only one fluorescence ratio could not be accomplished.
\end{abstract}

Keywords: blue-green fluorescence; chlorophyll fluorescence; abiotic stresses; biotic stresses; precision agriculture 


\section{Introduction}

Agronomic crops are exposed to a number of biotic and abiotic stresses which may induce considerable yield losses [1,2]. Under practical conditions, the negative impact of stresses can be restricted to a certain extent by cultivation and management practices such as appropriate use of fertilizers, irrigation, crop rotation or application of pesticides. Nevertheless, precise methods for stress sensing and differentiation are required particularly in those cases in which plants respond with similar symptoms across two or more stress conditions [3-5]. As outlined by Jones and Schofield [6] and Jones and Vaughan [7], remote sensing techniques possess promising potential in precision farming since they allow a fast and reliable monitoring of vegetation on a large scale [8,9]. With particular regard to the sensing of $\mathrm{N}$ status of the plant, fluorescence emission indices, recorded in the spectral wavelengths from 440-730 nm, seem to be more precise than some of the classical pulse amplitude modulated chlorophyll fluorescence (PAM) parameters [10]. Thereby, the chlorophyll fluorescence (ChlF) which is exclusively emitted by chlorophyll $a$ molecules, might be recorded in the red (F680) and the far-red (F730) spectral region by using different excitation light sources [11,12]. By using UV-irradiation, several phenolic substances, mainly located in the epidermal layers or leaf veins, emit a characteristic blue (F440) and green (F530) fluorescence [13]. Moreover, the ferulic acid covalently bound to the cell walls, is a major emitter of blue-green fluorescence (BGF) [14-16].

In general, fluorescence ratios are better suited for the remote sensing of plants compared to the absolute fluorescence intensities since the latter can vary considerably under changing measurement conditions or due to morpho-physiological variations of the plants [13,17]. The F690/F735 is a frequently used fluorescence ratio which reflects the chlorophyll fluorescence in the red and far-red spectral region. It has been shown that this ChlF-ratio decreases with increasing leaf chlorophyll concentration [18] and is therefore a reliable in vivo indicator of the chlorophyll content [19,20]. Further, Lichtenthaler and Rinderle [21] demonstrated the suitability of this ratio for the assessment of the photosynthetic activity. Because of the positive correlation between leaf chlorophyll and $\mathrm{N}$ content, Bredemeier and Schmidhalter [22] recognised this ratio as a potential tool for the side-specific $\mathrm{N}$ application in precision farming.

Langsdorf et al. [23] showed that lower N-supply increased the blue-to-red (F440/F690) and the blue-to-far-red (F440/F730) fluorescence ratio of sugar beet leaves. Similar observations were made by Heisel et al. [24] targeting detection of the nutrient deficiency of maize. Moreover, the fluorescence indices F440/F690 and F440/F730 rose in plants exposed to water deficit [25-27] and pathogen infection [28]. Recently, the "Nitrogen Balance Index" (NBI), a specific excitation-emission ratio which depends on epidermal phenolics and chlorophyll content [29,30], was proposed for non-destructive stress sensing. Nitrogen deficiency significantly decreases this ratio [31,32]. On the other hand, Bilger et al. [33] proposed the fluorescence excitation-emission ratio "FER_RUV" to estimate the effect of epidermal transmission of UV-radiation in leaves, and their ability for photoprotection.

As shown in the literature, the above mentioned fluorescence indices provided reliable information about the plant physiological status in response to changing environmental conditions or occurrence of stress. However, the majority of the studies were done by choosing one single stress, the other experimental conditions remaining constant, contrasting the situation under natural conditions, where 
plants are generally exposed to a multitude of interacting stress factors [5]. In order to overcome this shortcoming, we aimed to assess the fluorescence signature of sugar beet leaves in response to three single or interacting stresses, under similar conditions as they may happen in commercial production sites. For this purpose, we selected the factors water supply, N-supply as well as powdery mildew infection as economically and eco-physiologically relevant stresses. Based on our previous studies on sugar beet [34], and being aware that all the selected stresses might at least partially influence the photosynthetic performance and the chlorophyll fluorescence, we hypothesized that a pre-symptomatic stress differentiation of the individual stresses can be accomplished. In order to improve the experimental design, we selected two sugar beet cultivars, differing in their susceptibility to powdery mildew, which were individually grown in pots and allocated in a horticultural polytunnel.

\section{Material and Methods}

\subsection{Plant Material, Growth Conditions and Pathogen Inoculation}

Seeds of two sugar beet (Beta vulgaris L.) cultivars, Pauletta and Cesira, differing in their susceptibility degree (SD) to powdery mildew, were provided by the company KWS (KWS Saatgut AG, Einbeck, Germany). According to the descriptive list of the German Federal Plant Variety Office 2010, in a scale ranging from $1-9$, "Pauletta" $(\mathrm{SD}=6)$ is characterized as more susceptible to powdery mildew than "Cesira" $(\mathrm{SD}=4)$. Untreated seeds were sown in trays filled with a mixture of sand-peat as growing medium. Fourteen days after germination, uniform plants were thinned and individually transplanted into 4 liter plastic pots $(0.233 \mathrm{~m}$ height, $0.157 \mathrm{~m}$ diameter $)$, equally filled with a special nutrient-poor peat substrate (Einheitserde Typ 0, Einheitserde- und Humuswerke Gebr. Patzer GmbH \& Co. KG, Sinntal-Altengronau, Germany). Plants ( $n=8$ per cultivar and treatment) were placed at random in two individual horticultural polytunnels (each with a size of $5.8 \times 3.2 \times 2.3 \mathrm{~m}$ ) covered with UV-permeable Norton FEP-Film (FG perfluorethylenpropylene-copolymer). One tunnel was used exclusively for the pathogen inoculation in order to avoid accidental inoculation and infection of the powdery mildew-free treatments. The inoculation was done 29 days after sowing (DAS) by gently moving and slightly shaking infected sugar beet plants on top and along the experimental plants. Plants were fertilized by using commercial mineral fertilizers at rates of $100 \mathrm{~kg}$ $\mathrm{P}_{2} \mathrm{O}_{5} \mathrm{ha}^{-1}, 400 \mathrm{~kg} \mathrm{~K}_{2} \mathrm{O} \mathrm{ha}{ }^{-1}$ and $85 \mathrm{~kg} \mathrm{MgO} \mathrm{ha}^{-1}$, after the first leaf pair was unfolded (21 DAS). Thereby, two levels of nitrogen supply were established: the lower dose of $50 \mathrm{~kg} \mathrm{~N} \mathrm{ha}^{-1}$ (ND, nitrogen deficit) and a high dose of $150 \mathrm{~kg} \mathrm{~N} \mathrm{ha}^{-1}$. A lack of micronutrients was avoided by watering all plants with $50 \mathrm{~mL}$ nutrient solution (pH 6.5 and an EC $180 \mathrm{mS} \mathrm{cm}^{-1}$ ) twice (21 and 30 DAS). Plants were regularly watered by using a drip irrigation system; water deficit was induced by withholding the water from 32 to 47 DAS. Treatments investigated in this study are shown in Table 1. 
Table 1. Short description of the treatment groups and the respective abbreviations.

\begin{tabular}{cc}
\hline Abbreviation & Treatment Description \\
\hline C & Control plants were regularly watered and received $150 \mathrm{~kg} \mathrm{~N} \mathrm{ha}^{-1}$ \\
ND & Lower N treated plants were regularly watered but received only $50 \mathrm{~kg} \mathrm{~N} \mathrm{ha}^{-1}$ \\
PM & Powdery mildewed plants were inoculated at 29 DAS and handled similarly as control plants \\
WD & Water deficit was started at 32 DAS and plants received $150 \mathrm{~kg} \mathrm{~N} \mathrm{ha}^{-1}$ \\
PM-ND & Combination of powdery mildew and lower N-supply \\
WD-ND & Combination of water deficit and lower N-supply \\
WD-PM & Combination of water deficit and powdery mildew \\
WD-PM-ND & Combination of water deficit, powdery mildew and lower N-supply \\
\hline
\end{tabular}

\subsection{Non-Destructive Measurements}

\subsubsection{Portable Multiparametric Fluorescence Sensor}

A hand-held multiparametric fluorescence sensor (Multiplex ${ }^{\circledR}$ 3, Force-A, Orsay, France) was used to record the fluorescence at leaf level. Light-emitting-diodes excited the fluorescence at $375 \mathrm{~nm}$ (UV), $518 \mathrm{~nm}$ (green) and $630 \mathrm{~nm}$ (red) while the emitted fluorescence light was detected in the blue (BGF: 425-475 nm), red (RF: 680-690 nm) and far-red (FRF: 720-755 nm) spectral regions. Different excitation and emission channels result in more than 12 signals. The used fluorescence indices were derived according to the respective formula:

$$
\begin{aligned}
& \text { SFR_G }=\text { FRF_G/RF_G } \\
& \text { NBI_G }=\text { FRF_UV/FR_G } \\
& \text { FER_RUV }=\text { FRF_R/FRF_UV } \\
& \text { BFRR = BGF_UV/FRF_UV }
\end{aligned}
$$

A detailed technical description of the portable fluorescence sensor and the explanation of the individual fluorescence indices are provided by Ben Gholzen et al. [35] and Cerovic et al. [29]. In our equipment a grid in front of the sensor enabled the illumination of an area of approximately $0.005 \mathrm{~m}^{2}$ by maintaining a constant distance of $10 \mathrm{~cm}$ between sensor and leaf surface. Fluorescence readings were taken from leaves of the second leaf pair at 34 and 41 DAS (BBCH stage 14, BBCH being the official German identification code to identify the phenologic growth stages of plants), and the third leaf pair at 43 and 47 DAS (BBCH stage 16), respectively.

\subsubsection{Laboratory Multispectral Fluorescence Imaging}

For a better understanding of the stress related changes in the fluorescence characteristics, fluorescence images were recorded on attached leaves with the multispectral fluorescence imaging system Nuance $^{\circledR}$ TM FX (Caliper Life Sciences, PerkinElmer, MA, USA). For this purpose representative plants were transported to the laboratory at 41 and 47 DAS. The fluorescence system comprises a 1.4 megapixel CCD camera and the equipment-specific software (Nuance ${ }^{\circledR} 2.4$ imaging software, Caliper Life Sciences, PerkinElmer, MA, USA). The camera was mounted onto a stereomicroscope (Zeiss SteREO Lumar V12, Jena, Germany) equipped with a filter wheel containing 
three Zeiss Lumar filters (01, 09 and 14). With this setup, the fluorescence can be excited in spectral ranges about $365 \pm 12 \mathrm{~nm}$ (UV), 450-490 nm (blue) and 510-560 nm (green). According to the filter used, the emitted fluorescence light can be measured by long-pass emission filters at $397 \mathrm{~nm}$ (UV-excitation), $515 \mathrm{~nm}$ (blue-excitation) and $590 \mathrm{~nm}$ (green-excitation), respectively. Fluorescence data were acquired using a $0.8 \mathrm{X}$ Zeiss Neo Lumar objective with a free working distance of $0.08 \mathrm{~mm}$. A cold-light (LQ-HXP 120, Leistungselektronik Jena, Germany) equipped with a mercury short-arc lamp (Osram, HXP R 120W/45C UV, München, Germany) was used as light source. Images were recorded by using the highest light intensity $\left(303.45 \mathrm{~W} \mathrm{~m}^{-2}\right.$ at leaf level). Before measurements, intact leaves were fixed employing a vacuum sample holder, which allows the recording of clear images from a flat leaf surface. An object field of $110.25 \mathrm{~mm}^{2}$ was illuminated using a $11 \times$ magnification and a focus of $51.4 \mathrm{~mm}$. Fluorescence intensities were recorded under UV-excitation in $10 \mathrm{~nm}$ steps for the following spectral ranges: 420-500 nm (blue), 500-580 nm (green) and from 620-720 nm (red). Fluorescence images were always recorded under standardized conditions in the dark at $21^{\circ} \mathrm{C}$ by using the full CCD frame $(1392 \times 1040$ pixels $)$. Before recording, the equipment automatically set the optimum exposure time in order to get reliable and strong fluorescence signals for each wavelength range.

\subsection{Biochemical Indicators}

\subsubsection{Sampling Methodology}

Reference parameters were obtained from leaves sampled at 41 and 47 DAS. For this purpose, the leaves previously used for the fluorescence readings were harvested and stored at $-21{ }^{\circ} \mathrm{C}$ in bags for later determination of osmotic potential. Before freezing, a leaf section of $130 \mathrm{~mm}^{2}$ was punched out from the apex of one leaf per plant for subsequent determination of chlorophyll concentration. The effects of multiple stresses on above ground biomass production were assessed by harvesting and weighting (Kern EV 4200-2NM, Balingen, Germany) the remaining sugar beet leaves at 47 DAS.

\subsubsection{Chlorophyll Concentration}

Immediately after sampling, leaf sections were transferred into $10 \mathrm{~mL}$ centrifugal vials filled with $5 \mathrm{~mL}$ dimethyl sulfoxide (DMSO). Afterwards, vials were closed and dark-stored for $24 \mathrm{~h}$ under laboratory conditions to extract the chlorophyll from the tissue by avoiding its uncontrolled degradation due to light exposition. A UV-VIS spectrophotometer (Perkin-Elmer, Lambda 5, MA, USA) was used to determine the chlorophyll concentration by measuring the absorbance of extracts at $665 \mathrm{~nm}$ (A665) and $647 \mathrm{~nm}$ (A647). Chlorophyll $a$ (Chl a) and chlorophyll $b(\mathrm{Chl} \mathrm{b})$ concentrations were calculated according to the following equations [36]:

$$
\begin{aligned}
& \mathrm{Chl} \mathrm{a}=12.7 \times \mathrm{A} 665-2.79 \times \mathrm{A} 647 \\
& \mathrm{Chl} \mathrm{b}=20.7 \times \mathrm{A} 647-4.64 \times \mathrm{A} 665
\end{aligned}
$$




\subsubsection{Osmotic Potential}

Freeze-stored samples were defrosted at room temperature and extruded with a hand homogenizer. Thereafter, a volume of approximately $0.5 \mathrm{~mL}$ was filled into $1.5 \mathrm{~mL}$ tubes, and the cell sap was centrifuged (Heraeus Biofuge Pico, Kendro Laboratory Products, Newtown, USA) for 5 min with a relative centrifugal force of $16,060 \times g$. From the supernatant, $15 \mu \mathrm{L}$ were transferred into $0.5 \mathrm{~mL}$ Eppendorf tubes and the osmolality measured with a freezing-point depression osmometer (Osmomat 030-D, Genotec GmbH, Berlin, Germany).

\subsection{Statistical Analysis}

Data were statistically analyzed with (SPSS) statistic software (PASW statistics version 19.0, SPSS Inc., Chicago, IL, USA). ANOVA and sequential Duncan post-hoc analysis was used for treatment comparison within each cultivar and evaluation date. The results are expressed as mean \pm standard error (SE), and the level of statistical significance of differences is $p \leq 0.05$.

\section{Results}

\subsection{Multiparametric Fluorescence}

\subsection{1. "Simple Fluorescence Ratio" (SFR_G)}

Figure 1 displays the impact of treatments on the SFR_G for both cultivars at two leaf stages: BBCH 14 (34 and 41 DAS) and BBCH 16 (43 and 47 DAS). As shown, in most cases the control treatment displayed the highest SFR_G. Fluorescence readings on the second leaf pair displayed a strong decrease of SFR_G from 34 DAS to 41 DAS, irrespective of the experimental treatment. In "Cesira", plants of the control and low N-supply (ND) treatments did not show any significant differences, irrespective of leaf stage. All other treatments had by trend a lower SFR_G. SFR_G of "Pauletta" displayed nearly the same trend as "Cesira". Nevertheless, slight differences were seen at 34 and 43 DAS, when significant differences between the control and the low N-supply plants were detected (Figure 1). The strongest impact of the applied treatments was observed for both cultivars at 47 DAS. Here, water deficit (WD) and water deficit combined with powdery mildew (WD-PM) resulted in a considerable decrease of SFR_G. 
Figure 1. Influence of N-supply (ND), powdery mildew (PM), water deficit (WD), or combined stresses (PM-ND, WD-ND, WD-PM, WD-PM-ND) on the simple fluorescence ratio excited with green light (SFR_G) of the sugar beet cultivars Pauletta and Cesira. Fluorescence readings were taken on the second leaf pair at 34 and $41 \mathrm{DAS}$, and on the third leaf pair at 43 and 47 DAS. Values indicate mean \pm SE $(n=16)$. Letters (case sensitive) indicate significant differences among the treatment groups for each cultivar $(p \leq 0.05$, Duncan's test).
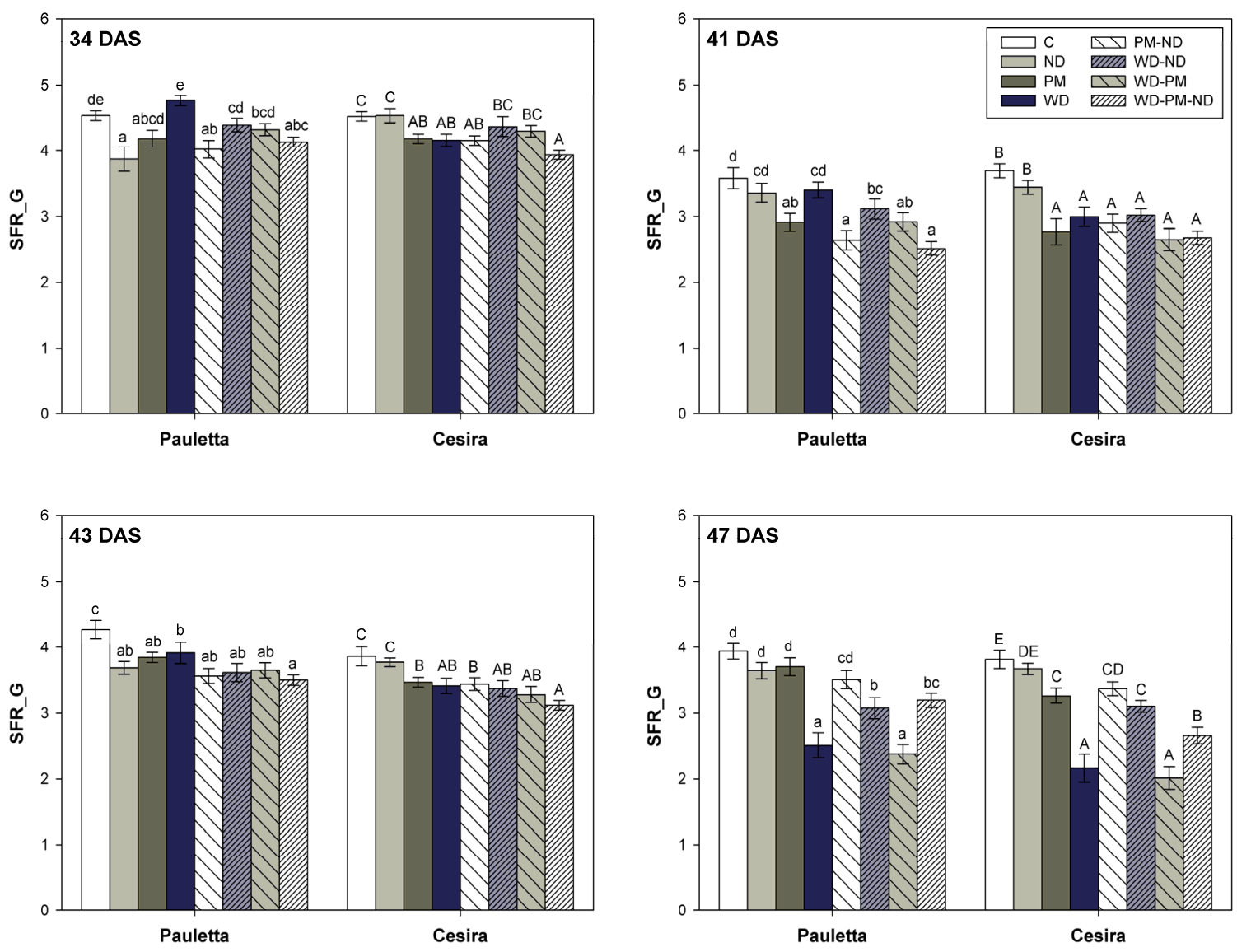

\subsubsection{Fluorescence Excitation Ratio (FER_RUV)}

Irrespective of the cultivar, with the FER_RUV we were not able to detect any significant differences among the treatments at 34 DAS (Figure 2). This was also the case for "Cesira" at 41 and 43 DAS. However, the combinations of powdery mildew + lower N-supply (PM-ND) as well as water deficit + powdery mildew (WD-PM) induced a strong increase of FER_RUV in "Pauletta" at 41 DAS (Figure 2). Revealed by higher FER_RUV intensities at 43 and 47 DAS, fluorescence measurements confirm previous indications which indicate a stronger stress response in the leaves of "Pauletta" than in those of "Cesira". 
Figure 2. Influence of N-supply (ND), powdery mildew (PM), water deficit (WD), or combined stresses (PM-ND, WD-ND, WD-PM, WD-PM-ND) on the fluorescence excitation ratio (FER_RUV) of the sugar beet cultivars Pauletta and Cesira. Fluorescence readings were taken on the second leaf pair at 34 and 41 DAS, and on the third leaf pair at 43 and 47 DAS. Values indicate mean \pm SE $(n=16)$. Letters (case sensitive) indicate significant differences among the treatments for each cultivar ( $p \leq 0.05$, Duncan's test); * ns, non-significant according to the analysis of variance (ANOVA).
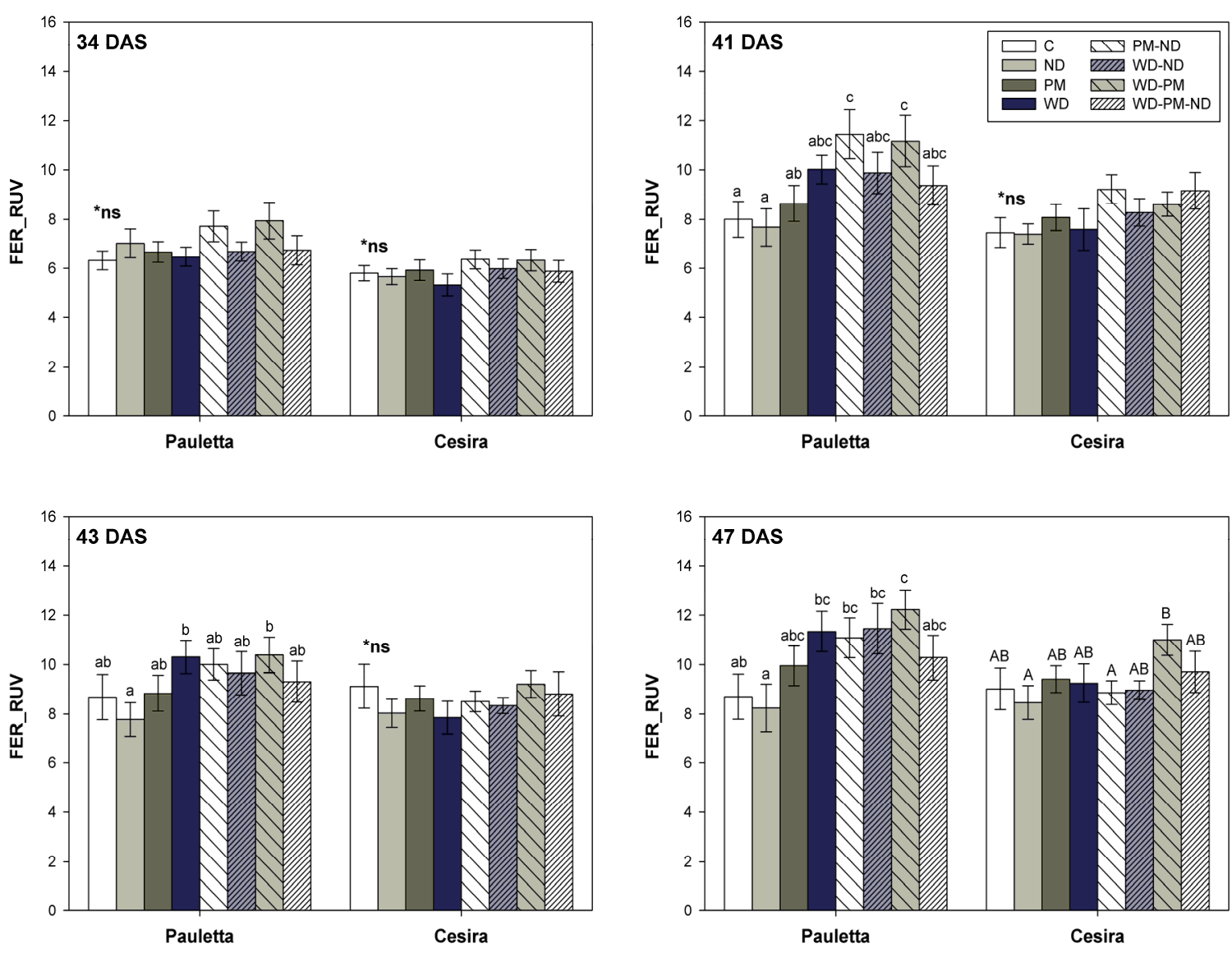

\subsubsection{Nitrogen Balance Index (NBI_G)}

The NBI_G decreased in both "Pauletta" and "Cesira" from 34 DAS to 41 DAS (Figure 3). In "Pauletta", with exception of WD all the treatments led to a decrease of NBI_G at 34 DAS; in "Cesira", the combined stress factors PM-ND, WD-ND, WD-PM, and WD-PM-ND induced a stronger decrease of NBI_G. Similarities in the response of both cultivars were also observed at 41 DAS. Here, the occurrence of multiple stresses decreased the NBI_G to values below the control and low N-supply (Figure 3). Measurements at the third leaf, at 43 DAS, confirmed the trends observed before, particularly for "Pauletta". Determinations at 47 DAS indicate comparable results on the effects of single and combined stresses in both cultivars. Thereby, plants exposed to water deficit (WD) alone or combined with powdery mildew (WD-PM) had the strongest decrease of NBI_G. On the other hand, no differences could be detected between the control and low N-supply (ND) treatment (Figure 3). 
Figure 3. Influence of N-supply (ND), powdery mildew (PM), water deficit (WD), or combined stresses (PM-ND, WD-ND, WD-PM, WD-PM-ND) on the nitrogen balance index excited with green light (NBI_G) of the sugar beet cultivars Pauletta and Cesira. Fluorescence readings were taken on the second leaf pair at 34 and $41 \mathrm{DAS}$, and on the third leaf pair at 43 and 47 DAS. Values indicate mean \pm SE $(n=16)$. Letters (case sensitive) indicate significant differences among the treatments for each cultivar $(p \leq 0.05$, Duncan's test).
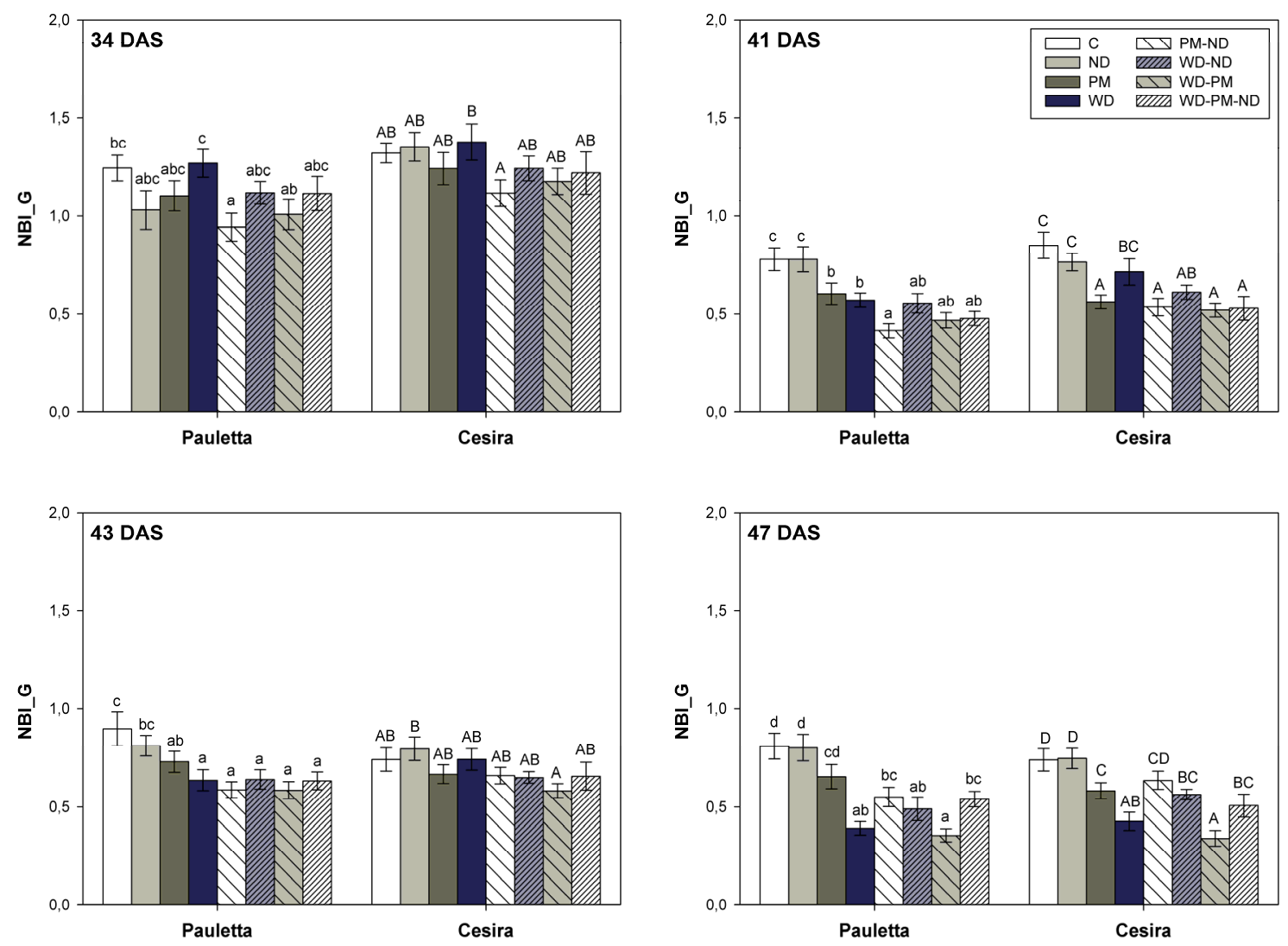

\subsubsection{Blue-to-Far-Red Fluorescence Ratio (BFRR_UV)}

The blue-to-far-red fluorescence ratio revealed a significant impact of the N-supply in leaves of "Pauletta" as well as the effect of water deficit in combination with a low N-supply in leaves of "Cesira" at 34 DAS (Figure 4). Particularly at 41 and 47 DAS, the cultivar Pauletta responded with a stronger increase in BFRR_UV than the cultivar Cesira. Here, the powdery mildew triggered the increase of the values, especially when associated with lower N-supply (PM-ND). At 47 DAS, when the water deficit stress was at its highest, both powdery mildew (PM) and water deficit (WD), alone or in combination (WD-PM), raised the BFRR_UV in "Pauletta". The same stress factors affected the cultivar Cesira, although at lower intensity. 
Figure 4. Influence of N-supply (ND), powdery mildew (PM), water deficit (WD), or combined stresses (PM-ND, WD-ND, WD-PM, WD-PM-ND) on the blue-to-far-red fluorescence ratio (BFRR_UV) of the sugar beet cultivars Pauletta and Cesira. Fluorescence readings were taken on the second leaf pair at 34 and 41 DAS, and on the third leaf pair at 43 and 47 DAS. Values indicate mean \pm SE $(n=16)$. Letters (case sensitive) indicate significant differences among the treatments for each cultivar $(p \leq 0.05$, Duncan's test).
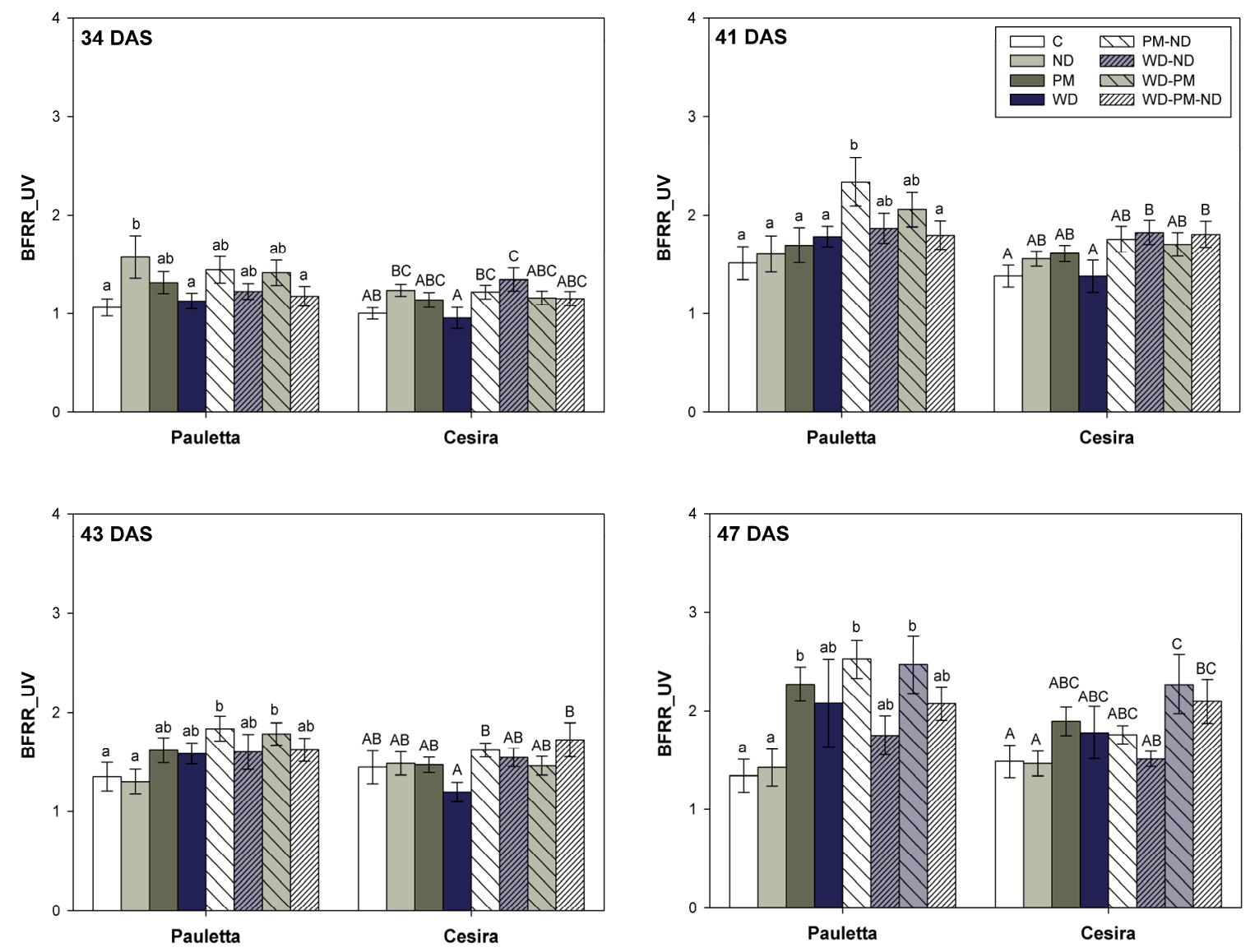

\subsubsection{Temporal Sensitivity of the Selected Fluorescence Indices}

In a simplified way, Table 2 displays the sensitivity of the SFR_G, FER_UV, NBI_G and BFRR_UV by presenting the occurrence of significant differences between control and stress-exposed plants at the four measurement dates. Particularly the SFR_G and the NBI_G were highly sensitive and might be adopted to indicate the effect of PM or WD and multiple stresses, such as PM-ND, WD-ND, WD-PM, WD-PM-ND. As one example, PM-ND was detected with the SFR_G on leaves of both cultivars already at 34 DAS (Table 2). In the further course of the study, nearly all stress related differences in the fluorescence signature could be sensed by using the SFR_G and NBI_G. 
Table 2. Development of the temporal sensitivity of fluorescence indices for sensing single and combined abiotic and biotic stresses on sugar beet leaves of the cultivars Pauletta and Cesira. (x) indicates significant differences between control and stress-exposed leaves (ANOVA, $p \leq 0.05$ ).

\begin{tabular}{|c|c|c|c|c|c|c|c|c|c|c|c|c|c|c|c|c|}
\hline & \multicolumn{8}{|c|}{ BBCH Stage 14} & \multicolumn{8}{|c|}{ BBCH Stage 16} \\
\hline & \multicolumn{4}{|c|}{$\begin{array}{c}34 \text { DAS } \\
\text { Fluorescence Indices * }\end{array}$} & \multicolumn{4}{|c|}{$\begin{array}{c}41 \text { DAS } \\
\text { Fluorescence Indices * }\end{array}$} & \multicolumn{4}{|c|}{$\begin{array}{l}43 \text { DAS } \\
\text { Fluorescence Indices * }\end{array}$} & \multicolumn{4}{|c|}{$\begin{array}{c}47 \text { DAS } \\
\text { Fluorescence Indices * }\end{array}$} \\
\hline & SFR & FER & NBI & BFRR & SFR & FER & NBI & BFRR & SFR & FER & NBI & BFRR & SFR & FER & NBI & BFRR \\
\hline Pauletta ND & $\mathrm{x}$ & & & $\mathrm{x}$ & & & & & $\mathrm{x}$ & & & & & & & \\
\hline PM & & & & & $\mathrm{x}$ & & $\mathrm{x}$ & & $\mathrm{x}$ & & $\mathrm{x}$ & & & & & $\mathrm{x}$ \\
\hline WD & & & & & & & $\mathrm{x}$ & & $\mathrm{x}$ & $\mathrm{x}$ & $\mathrm{x}$ & & $\mathrm{x}$ & & $\mathrm{x}$ & \\
\hline PM-ND & $\mathrm{x}$ & & $\mathrm{x}$ & & $\mathrm{x}$ & $\mathrm{x}$ & $\mathrm{x}$ & & $\mathrm{x}$ & & $\mathrm{x}$ & $\mathrm{x}$ & & & $\mathrm{x}$ & $\mathrm{x}$ \\
\hline WD-ND & & & & & $\mathrm{x}$ & & $\mathrm{x}$ & $\mathrm{x}$ & $\mathrm{x}$ & & $\mathrm{x}$ & & $\mathrm{x}$ & & $\mathrm{x}$ & \\
\hline WD-PM & & & & & $\mathrm{x}$ & $\mathrm{x}$ & $\mathrm{x}$ & & $\mathrm{x}$ & $\mathrm{x}$ & $\mathrm{x}$ & $\mathrm{x}$ & $\mathrm{x}$ & $\mathrm{x}$ & $\mathrm{x}$ & $\mathrm{x}$ \\
\hline WD-PM-ND & $\mathrm{x}$ & & & & $\mathrm{x}$ & & $\mathrm{x}$ & & $\mathrm{x}$ & & $\mathrm{x}$ & & $\mathrm{x}$ & & $\mathrm{x}$ & \\
\hline \multicolumn{17}{|l|}{ Cesira ND } \\
\hline PM & $\mathrm{x}$ & & & & $\mathrm{x}$ & & $\mathrm{x}$ & & $\mathrm{x}$ & & & & $\mathrm{x}$ & & $\mathrm{x}$ & \\
\hline WD & $\mathrm{x}$ & & & & $\mathrm{x}$ & & & & $\mathrm{x}$ & & & & $\mathrm{x}$ & & $\mathrm{x}$ & \\
\hline PM-ND & $\mathrm{x}$ & & & & $\mathrm{x}$ & & $\mathrm{x}$ & & $\mathrm{x}$ & & & & $\mathrm{x}$ & & & \\
\hline WD-ND & & & & $\mathrm{x}$ & $\mathrm{x}$ & & $\mathrm{x}$ & $\mathrm{x}$ & $\mathrm{x}$ & & & & $\mathrm{x}$ & & $\mathrm{x}$ & \\
\hline WD-PM & & & & & $\mathrm{x}$ & & $\mathrm{x}$ & & $\mathrm{x}$ & & & & $\mathrm{x}$ & & $\mathrm{x}$ & $\mathrm{x}$ \\
\hline WD-PM-ND & $\mathrm{x}$ & & & & $\mathrm{x}$ & & $\mathrm{x}$ & $\mathrm{x}$ & $\mathrm{x}$ & & & & $\mathrm{x}$ & & $\mathrm{x}$ & $\mathrm{x}$ \\
\hline
\end{tabular}

*SFR = SFR_G; FER = FER_RUV; NBI = NBI_G; BFRR = BRR_UV. 


\subsection{Fluorescence Imaging}

Fluorescence images recorded from representative plants at 41 and 47 DAS provide supporting material for a better understanding of the multiparametric fluorescence readings in the field. In general, blue and green fluorescence intensities of "Cesira" were rather weak compared to "Pauletta" (Table 3). Fluorescence signals were significantly higher in powdery mildew infected plants compared to the control or to plants receiving low N-supply. In both cultivars, the blue-to-green ratios displayed slight differences between water deficit (WD) and control plants. Particularly at 47 DAS a strong decline in the chlorophyll fluorescence intensity in low N-supply plants (ND), also when combined with powdery mildew (PM-ND), was visualized. Our images confirm that particularly the blue fluorescence was higher in the powdery mildew infected leaves, leading to higher blue-to-red fluorescence ratios (BF/RF) in those plants (Figure 5).

Table 3. Blue (BF), green (GF) and red (RF) fluorescence intensities, as well as blue-to-green $(\mathrm{BF} / \mathrm{GF})$ and blue-to-red $(\mathrm{BF} / \mathrm{RF})$ fluorescence ratios, of sugar beet leaves at 41 and 47 DAS. Absolute fluorescence intensities were recorded under UV excitation with the Nuance ${ }^{\circledR}$ fluorescence imaging system. Absolute fluorescence intensities (BF, GF, RF) are represented as average signal (scaled counts $/ \mathrm{s} \times 1000$ ).

\begin{tabular}{|c|c|c|c|c|c|c|c|c|c|c|c|}
\hline \multirow{2}{*}{\multicolumn{2}{|c|}{ Treatment }} & \multicolumn{5}{|c|}{41 DAS } & \multicolumn{5}{|c|}{47 DAS } \\
\hline & & BF & GF & RF & $\begin{array}{c}\text { BF/GF } \\
\text { Ratio }\end{array}$ & $\begin{array}{c}\text { BF/RF } \\
\text { Ratio }\end{array}$ & BF & GF & $\mathbf{R F}$ & $\begin{array}{c}\text { BF/GF } \\
\text { Ratio }\end{array}$ & $\begin{array}{c}\text { BF/RF } \\
\text { Ratio }\end{array}$ \\
\hline \multirow{8}{*}{ 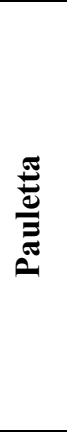 } & $\mathrm{C}$ & 0.3 & 3.8 & 53.4 & 0.09 & 0.01 & 0.3 & 2.6 & 68.1 & 0.13 & 0.00 \\
\hline & ND & 0.5 & 1.4 & 42.5 & 0.34 & 0.01 & 0.4 & 5.4 & 1.3 & 0.08 & 0.34 \\
\hline & PM & 42.4 & 117 & 65.4 & 0.36 & 0.65 & 185.2 & 286.1 & 76.5 & 0.65 & 2.42 \\
\hline & WD & 3.2 & 31.5 & 48.8 & 0.10 & 0.07 & 3.2 & 46.2 & 65.4 & 0.07 & 0.05 \\
\hline & PM-ND & 13.6 & 62.2 & 52.3 & 0.22 & 0.26 & 50.9 & 116.2 & 7.8 & 0.44 & 6.53 \\
\hline & WD-ND & 3.0 & 8.1 & 1.0 & 0.37 & 3.03 & 3.6 & 23.5 & 54.3 & 0.15 & 0.07 \\
\hline & WD-PM & 18.3 & 47.1 & 24.0 & 0.39 & 0.76 & 137.7 & 141.9 & 61.6 & 0.97 & 2.23 \\
\hline & WD-PM-ND & 32.3 & 84.4 & 44.1 & 0.38 & 0.73 & 37.3 & 83.0 & 57.3 & 0.45 & 0.65 \\
\hline \multirow{8}{*}{ 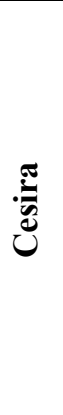 } & $\mathrm{C}$ & 0.4 & 5.7 & 99.9 & 0.07 & 0.00 & 0.8 & 3.8 & 48.8 & 0.21 & 0.02 \\
\hline & ND & 0.6 & 1.9 & 51.7 & 0.33 & 0.01 & 0.5 & 1.8 & 10.4 & 0.63 & 0.05 \\
\hline & PM & 38.9 & 115.8 & 72.6 & 0.34 & 0.54 & 30.7 & 81.9 & 62.5 & 0.37 & 0.49 \\
\hline & WD & 2.8 & 46.8 & 29.4 & 0.06 & 0.10 & 3.4 & 33.6 & 61.5 & 0.10 & 0.06 \\
\hline & PM-ND & 37.7 & 79.7 & 60.0 & 0.47 & 0.63 & 12.3 & 30.4 & 32.5 & 0.40 & 0.38 \\
\hline & WD-ND & 3.2 & 22 & 47.6 & 0.14 & 0.07 & 2.9 & 6.4 & 49.3 & 0.45 & 0.06 \\
\hline & WD-PM & 12.5 & 48.8 & 63.5 & 0.26 & 0.20 & 4.4 & 42.0 & 74.7 & 0.10 & 0.06 \\
\hline & WD-PM-ND & 5.7 & 18.5 & 49.8 & 0.31 & 0.11 & 6.2 & 36.7 & 60.0 & 0.17 & 0.10 \\
\hline
\end{tabular}


Figure 5. Blue, green and far-red (chlorophyll) fluorescence images of representative sugar beet leaves of the cultivar Cesira: control, powdery mildewed and water deficit leaves at 47 DAS. Images were recorded under UV excitation with a Zeiss ApoLumar S objective (focus of 17.29 , magnification of $85 \times$, light intensity of $98429 \mu \mathrm{W} \mathrm{cm}{ }^{-2}$ at leaf level).

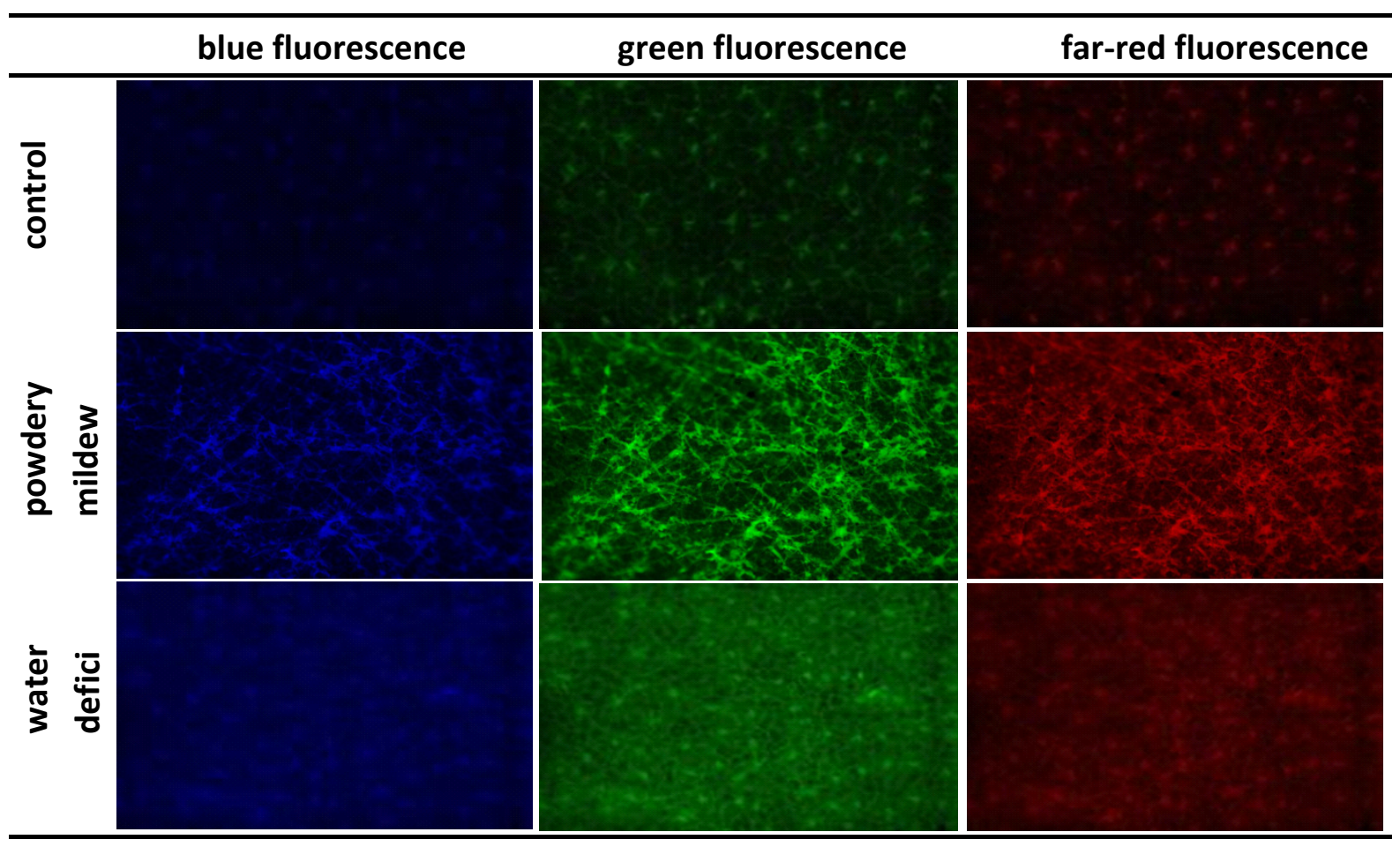

\subsection{Reference Parameters}

The osmotic potential and the total chlorophyll concentration were analyzed from leaves sampled at 41 and 47 DAS, while the above ground biomass was assessed at 47 DAS (Figure 6). The analyses at 41 DAS indicate that the osmotic potential was affected in both cultivars when plants were exposed to water deficit (WD) or water deficit + powdery mildew (WD-PM). A significant rise of the osmotic potential in these treatments was also detected at 47 DAS. In contrast to the other experimental treatments, lower N-supply (ND) reduced only slightly the total chlorophyll concentration in leaves of "Pauletta" and "Cesira". In general, "Pauletta" had a more pronounced decrease in the total chlorophyll concentration as compared to "Cesira" (Figure 6). Also, water deficit (WD) considerably impacted the total chlorophyll concentration in a negative way at 47 DAS in both cultivars. Further comparisons showed no significant effect of powdery mildew (PM) on the above ground biomass production. In contrast, all other treatments restricted the biomass accumulation in both cultivars (Figure 6). 
Figure 6. Influence of single or combined stresses on the osmotic potential, total chlorophyll content and above ground biomass production at 41 and 47 DAS of the cultivar Pauletta (top) and Cesira (bottom). Treatment groups: N-level (ND), powdery mildew (PM), water deficit (WD), or combined stresses. Figures illustrate the relative changes (\%) of the stressed to the control plants of each cultivar. Values indicate mean $\pm \mathrm{SE}(n=8)$; asterisks indicate significant differences among the treatments and the control (ANOVA, $p \leq 0.05)$.
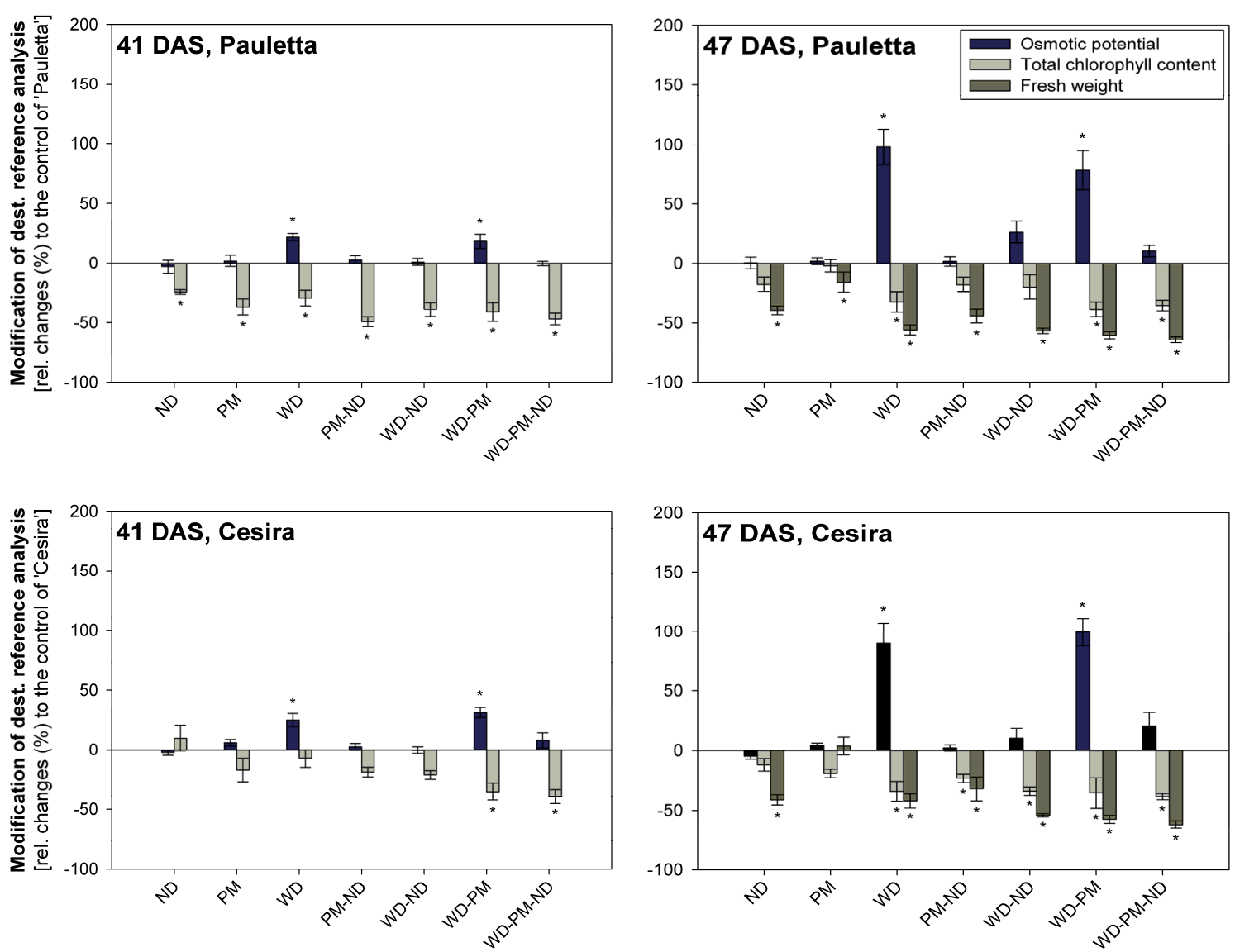

\section{Discussion}

In this study we investigated, whether the fluorescence indices SFR_G, NBI_G, BFFR_UV, and FER_RUV are suited to assess the impact of multiple stresses on two sugar beet cultivars. Thereby, we hypothesized that these indices allow a differentiation of the individual stresses despite the potential similarity of their effects on the plant physiology and fluorescence signature. Besides interesting and promising results, our working hypothesis could not be confirmed.

The impact of single stresses, as water deficit or powdery mildew, could be detected in the cultivar Cesira by using the SFR_G at 34 DAS (Table 2). However, the similar decrease in the fluorescence intensity hindered the differentiation of both stresses. This fact was an overall obstacle in our study and was also observed for combined stresses such as PM-ND, WD-ND and WD-PM-ND. One possible explanation for these observations is that all chosen stresses reduce plant photosynthetic 
efficiency [37-39], and the differentiation becomes more complicated due to the interaction of specific processes of the individual stresses [40,41].

Among all evaluated fluorescence indices, the SFR_G and the NBI_G were quite sensitive to stress and strain intensity (Table 2). The SFR_G roughly corresponds to the inverse ratio of F680/F730 ratio, and allows information about the chlorophyll content in vivo [19,20]. However, in our studies an overall significant correlation between SFR_G and total chlorophyll concentration was only found in non-irrigated (WD) plants of "Cesira" at 41 and 47 DAS, as well as for "Pauletta" at 47 DAS (data not shown). This suggests that decrease of SFR_G was mainly caused by alterations of the electron flow and other processes in the photosynthetic apparatus [21,30]. Later, with increasing dehydration, SFR_G values dropped stronger due to a decline in the chlorophyll concentration resulting from damages to the chloroplasts caused e.g., by active oxygen species [42]. Our assumption was supported by the stronger increase of the red fluorescence intensity than the far-red fluorescence intensity (data not shown), indicating that decline in the SFR_G was initiated by an inhibition of PSII [43]. In contrast to Valentini et al. [44], who challenged the effectiveness of this ratio as an early stress indicator, we have clearly shown that modifications in the SFR depended also on the tested cultivars. The higher susceptibility of "Cesira" to water deficit, here starting after our first recording, was also noticed in previous findings and confirms the usefulness of SFR_G [34].

Since N plays an important role for the chlorophyll synthesis $[45,46]$, we expected an influence of the N-supply on the ChlF. To our surprise, destructive chlorophyll analysis and recordings of the SFR did not show an overall effect of the lower N-supply (ND) on the chlorophyll concentration. Minor changes in the SFR_G were only noted on leaves of "Pauletta" at 34 and 43 DAS (Figure 1), indicating that this cultivar was more sensitive to a lower N-supply. These changes were driven by a decline in both the red fluorescence and the far-red fluorescence (data not shown), and are in agreement with the findings of Chappelle et al. [47]. Contrasting this, above ground biomass was significantly influenced by N-supply at 47 DAS (Figure 6). This unexpected result can be explained by the lower sensitivity of younger leaves to a nitrogen shortage [24], or due to the reallocation of $\mathrm{N}$ from older to younger leaves [48]. The higher $\mathrm{N}$ availability for the control plants enabled the production of more aboveground biomass, which may have influenced the leaf area [49,50]. Finally, it can be assumed that the real nitrogen deficit was not as strong as expected.

Cultivar specific differences against powdery mildew were only shown by a strong decline in the chlorophyll concentration in mildewed leaves of "Pauletta" at 41 DAS (Figure 6). Moreover, SFR_G values of mildew-infected leaves show a negative trend, irrespective of the cultivar (Figure 1). As outlined by Gordon and Duniway [39], net photosynthesis in mildewed sugar beet leaves is reduced by an affected mesophyll conductance, accelerating senescence. In general reduced chlorophyll concentration limits the energy transfer between the photosystem II and photosystem I, and induces alterations in the ChlF intensity, as also shown in our group for winter wheat [51].

Analogous to the SFR_G, NBI_G values of both cultivars enabled the sensing of stress and its intensity (Table 2). This fact is not surprising, as the NBI_G is influenced by both chlorophyll and flavonol content. The main advantage of this ratio is the utilization of UV and green light for fluorescence excitation. Since the later penetrates deeper in the leaf tissue, as compared to UV-light, it enables information about the ChlF which also comes from deeper tissue layers [52]. In our trials, water deficit significantly reduced the NBI_G of "Pauletta" (Figure 3) driven by a continuous decline 
in the UV excited far-red fluorescence (data not shown). Cartelat et al. [32] outlined that several strains may influence the synthesis of polyphenols, including hydroxycinnamic acids and flavonoids. Hence, the reduced ChlF can be attributed to an accumulation of such compounds which operate as a photoprotection-system that absorbs the UV-radiation in the epidermal layers [17]. Water deficit or water deficit combined with powdery mildew (WD-PM) caused a strong decline of the NBI_G in both cultivars, till harvest at 47 DAS (Figure 3). Analytical determinations confirm the induced drought-stress. The high osmotic potential (Figure 6) was caused by the osmotic adjustment through accumulation of solutes in order to maintain a constantly high turgor [53].

Sensing the impact of low N-supply with the NBI_G was not successful in our study, irrespective of the cultivar (Table 2). However, powdery mildew significantly changed the NBI_G, in a similar way to that described for the SFR_G. In addition to the negative impact of the fungus on the photosynthesis and chlorophyll content, the accumulation of blue-green fluorescing defense substances such as salicylic acid and phenylpropanoid compounds [54-57], as well as the shielding of the plant tissue by the whitish mycelium of the fungus, may have contributed to a decline in the NBI_G [28]. Indications for the shielding effect were also observed in the fluorescence imaging recordings (Figure 5), resulting also in a strong increase of the blue and green fluorescence (Table 3). This supports the observed effects on BFRR_UV, particularly in the susceptible cultivar Pauletta at 47 DAS (Figure 4). Moreover, the clear impact of low N-supply in "Pauletta" is explained by smaller changes in the blue fluorescence as compared to the chlorophyll fluorescence at 34 DAS (data not shown). Similar results were reported by Heisel et al. [24] showing that the BGF is less influenced by the N-supply than the chlorophyll fluorescence.

The potential of the FER_RUV in proximal and remote sensing was previously illustrated by Apostol et al. [31], who used this parameter for estimation of the plant $\mathrm{N}$ status. In our study, individual stress detection by using this excitation ratio was not successful. However, we could show that the tested cultivars responded in a different way to the multiple stress situations (Figure 2). The more relevant stresses here were water deficit (WD) and powdery mildew (PM). Higher blue-green fluorescence intensities in sugar beet plants of "Pauletta" (Table 3) explain the differences between the cultivars.

In summary, the evaluated fluorescence indices provide reliable information about plant physiological modifications during and after stress exposure. While the hand-held sensor is a tool for practical use in the field, the fluorescence camera providing spectrally and spatially resolved information enables a more precise understanding of physiological and biochemical processes, particularly the interaction plant-pathogens. As one important outcome, we showed that WD led to a proportionally strong rise of the green fluorescence as compared to the blue fluorescence intensity (Table 3). Similar results were found by Chappele et al. [58] on water stressed soybean leaves. Such increase of green fluorescence might be caused by the accumulation of specific green fluorescing compounds. Amongst others, the flavonol quercetin is one possible emitter of the green fluorescence [59], also responsible for the BGF in sugar beet plants [60]. On this basis, we recognize the need for a more detailed exploration of the green fluorescence in future activities. 


\section{Conclusions}

Our results confirm the suitability of SFR_G, NBI_G, BFRR_UV, and FER_RUV to sense stress symptoms triggered by water deficiency, low N-supply, and powdery mildew. However, a robust differentiation by using only one of the proposed indices was not possible. The most relevant fluorescence indices to detect water deficit and or powdery mildew infection were the SFR_G and the NBI_G, particularly due to their strong relationship to the chlorophyll concentration. In general, water deficit was the stressor with a stronger influence on plant physiology. Nonetheless, stress intensity and duration, as well as the cultivar-specific responses, are relevant for the interpretation of such data especially in proximal and remote sensing. Our results elucidate the potential for using fluorescence-based indices in precision farming, including fertilization measures.

\section{Acknowledgments}

The authors are grateful to Britta Schulz and the company KWS Saat AG (Einbeck, Germany) for providing the seeds of sugar beet. Moreover, the anonymous reviewers are highly acknowledged for their constructive and relevant suggestions during the peer-review phase. This study is part of the CROPSENSe.net research project "Networks of excellence in agricultural and nutrition research", which is financially supported by the German Federal Ministry of Education and Research (BMBF 0315529) and the European Union for regional development (z1011bc001a).

\section{Author Contributions}

Georg Leufen conducted the experiments including data recording and analysis; Georg Noga provided the required research funds, gave scientific advice and contributed with manuscript proofreading; Mauricio Hunsche worked as advisor during the conduction of experiments and data interpretation, and contributed in writing and proofreading the manuscript.

\section{Conflicts of Interest}

The authors declare no conflict of interest.

\section{References}

1. Oerke, E.C. Crop losses to pests. J. Agr. Sci. 2006, 144, 31-43.

2. Boyer, J.S. Plant productivity and environment. Science 1982, 218, 443-448.

3. Hsiao, T.C. Plant responses to water stress. Ann. Rev. Plant Physio. 1973, 24, 519-570.

4. Krantz, B.A.; Melsted, S.W. Nutrient deficiencies in corn, sorghums, and small grains. In Hunger Signs in Crops, 3rd ed.; Sprague, H.B., Ed.; New York, NY, USA, 1964; pp. 25-57.

5. Chaerle, L.; Lenk, S.; Leinonen, I.; Jones, H.G.; Van Der Straeten, D.; Buschmann, C. Multi-sensor plant imaging: Towards the development of a stress-catalogue. Biotechnol. J. 2009, 4, 1152-1167.

6. Jones, H.G.; Schofield, P. Thermal and other remote sensing of plant stress. Gen. Appl. Plant Physiol. 2008, 34, 19-32. 
7. Jones, H.G.; Vaughan, R.A. Remote Sensing of Vegetation: Principles. In Techniques and Applications; Oxford University Press: Oxford, UK, 2010.

8. Günther, K.P.; Dahn, H.G.; Lüdeker, W. Remote sensing vegetation status by laser-induced fluorescence. Remote Sens. Environ. 1994, 47, 10-17.

9. Lichtenthaler, H.K.; Lang, M.; Sowinska, M.; Heisel, F.; Miehé, J.A. Detection of vegetation stress via a new high-resolution fluorescence imaging system. J. Plant Physiol. 1996, 148, 599-612.

10. Rambo, L.; Ma, B.L.; Xiong, Y.; Da Silvia, P.R.F. Leaf and canopy optical characteristics as crop-N-status indicators for field nitrogen management in corn. J. Plant Nutr. Soil Sci. 2010, 173, 434-443.

11. Lichtenthaler, H.K.; Subhash, N.; Wenzel, O.; Miehé, J.A. Laser-Induced imaging of blue/red and blue/far-red fluorescence ratios, F440/F690 and F440/F740, as a means of early stress detection in plants. In Proceedings of the IEEE International Geoscience and Remote Sensing Symposium, IGARSS'97, Remote Sensing-A Scientific Vision for Sustainable Development, Singapore, 3-8 August 1997; Volume 4, pp. 1799-1801.

12. Buschmann, C.; Langsdorf, G.; Lichtenthaler, H.K. Imaging of the blue, green and red fluorescence emission of plants: An overview. Photosynthetica 2000, 38, 483-491.

13. Cerovic, Z.G.; Samson, G.; Morales, F.; Tremblay, N.; Moya, I. Ultraviolet-induced fluorescence for plant monitoring: Present state and prospects. Agronomie 1999, 19, 543-578.

14. Lichtenthaler, H.K.; Schweiger, J. Cell wall bound ferulic acid, the major substance of the blue-green fluorescence emission of plants. J. Plant Physiol. 1998, 152, 272-282.

15. Meyer, S.; Cartelat, A.; Moya, I.; Cerovic, Z.G. UV-Induced blue-green and far-red fluorescence along wheat leaves: A potential signature of leaf ageing. J. Exp. Bot. 2003, 54, 757-769.

16. Morales, F.; Cerovic, Z.G.; Moya, I. Time-resolved blue-green fluorescence of sugar beet (Beta vulgaris L.) leaves: Spectroscopic evidence for the presence of ferulic acid as the main fluorophore in the epidermis. Biochim. Biophys. Acta 1996, 1273, 251-262.

17. Schweiger, J.; Lang, M.; Lichtenthaler, H.K. Differences in fluorescence excitation spectra of leaves between stressed and non-stressed plants. J. Plant Physiol. 1996, 148, 536-547.

18. Lichtenthaler, H.K.; Hák, R.; Rinderle, U. The chlorophyll fluorescence ratio F690/F730 in leaves of different chlorophyll content. Photosynth. Res. 1990, 25, 295-298.

19. D’Ambrosio, N.; Szabó, K.; Lichtenthaler, H.K. Increase of the chlorophyll fluorescence ratio F690/F735 during the autumnal chlorophyll breakdown. Rad. Environ. Bioph. 1992, 31, 51-62.

20. Hák, R.; Lichtenthaler, H.K.; Rinderle, U. Decrease of the chlorophyll fluorescence ratio F690/F730 during greening and development of leaves. Radiat. Environ. Bioph. 1990, 29, 329-336.

21. Lichtenthaler, H.K.; Rinderle, U. The role of chlorophyll fluorescence in the detection of stress conditions in plants. CRC Cr. Rev. Anal. Chem. 1988, 19, 29-85.

22. Bredemeier, C.; Schmidhalter, U. Laser-Induced chlorophyll fluorescence as a tool to determine the nitrogen status of wheat. In Proceedings of the 3rd European Conference on Precision Agriculture, Montpellier, France, 18-20 June 2001; Grenier, G., Blackmore, S., Eds.; Agro Montpellier: Montpellier, France, 2001; Volume 2, pp. 899-904.

23. Langsdorf, G.; Buschmann, C.; Sowinska, M.; Babani, F.; Mokry, M.; Timmermann, F.; Lichtenthaler, H.K. Multicolour fluorescence imaging of sugar beet leaves with different nitrogen status by flash lamp UV-excitation. Photosynthetica 2000, 38, 539-551. 
24. Heisel, F.; Sowinska, M.; Miehe, JA.; Lang, M.; Lichtenthaler, H.K. Detection of nutrient deficiencies of maize by laser induced fluorescence imaging. J. Plant Physiol. 1996, 148, 622-631.

25. Bürling, K.; Cerovic, Z.G.; Cornic, G.; Ducruet, J.M.; Noga, G.; Hunsche, M. Fluorescence-based sensing of drought-induced stress in the vegetative phase of four contrasting genotypes. Environ. Exp. Bot. 2013, 89, 51-59.

26. Dahn, H.G.; Günther, K.P.; Lüdeker, W. Characterization of drought stress of maize and wheat by means of spectral resolved laser induced fluorescence. EARSeL Adv. Remote Sens. 1999, 1, 12-19.

27. Lang, M.; Lichtenthaler, H.K.; Sowinska, M.; Heisel, F.; Miehe, J.A. Fluorescence imaging of water and temperature stress in plant leaves. J. Plant Physiol. 1996, 148, 613-621.

28. Lüdeker, W.; Dahn, H.G.; Günther, K.P. Detection of fungal infection of plants by laser-induced fluorescence: An attempt to use remote sensing. J. Plant Physiol. 1996, 148, 579-585.

29. Cerovic, Z.G.; Goutouly, J.P.; Hilbert, G.; Destrac-Irvine, A.; Martinon, V.; Moise, N. Mapping winegrape quality attributes using portable fluorescence-based sensors. In Proceedings of the FRUTIC 09, Conception, Chile, Progap INIA, Conception, Chile, January 2009; Best, S., Ed.; Instituto de Investigaciones Agropecuarias: Chillan, Chile, 2009; pp. 301-310.

30. Tremblay, N.; Wang, Z.; Cerovic, Z.G. Sensing crop nitrogen status with fluorescence indicators. A review. Agron. Sustain. 2012, 32, 451-464.

31. Apostol, S.; Viau, A.A.; Tremblay, N.; Briantais, J.M.; Prasher, S.; Parent, L.E.; Moya, I. Laser-induced fluorescence signatures as a tool for remote monitoring of water and nitrogen stresses in plants. Can. J. Remote Sens. 2003, 29, 57-65.

32. Cartelat, A.; Cerovic, Z.G.; Goulas, Y.; Meyer, S.; Lelarge, C.; Prioul, J.L.; Barbottin, A.; Jeuffroy, M.H.; Gate, P.; Agati, G.; et al. Optically assessed contents of leaf polyphenolics and chlorophyll as indicators of nitrogen deficiency in wheat (Triticum aestivum L.). Field Crops Res. 2005, 91, 35-49.

33. Bilger, W.; Johnsen, T.; Schreiber, U. UV-excited chlorophyll fluorescence as a tool for the assessment of UV-protection by epidermis of plants. J. Exp. Bot. 2001, 52, 2007-2014.

34. Leufen, G.; Noga, G.; Hunsche, M. Physiological response of sugar beet (Beta vulgaris) genotypes to a temporary water deficit, as evaluated with a multiparameter fluorescence sensor. Acta Physiol. Plant 2013, 35, 1763-1774.

35. Ben Ghozlen, N.; Cerovic, Z.G.; Germain, C.; Toutain, S.; Latouche, G. Non-destructive optical monitoring of grape maturation by proximal sensing. Sensors 2010, 10, 10040-10068.

36. Blanke, M.M. Determination of chlorophyll using DMSO. Wein-Wissenschaft 1992, 47, 32-35.

37. Evans, J.R. Photosynthesis and nitrogen relationships in leaves of $\mathrm{C}_{3}$ plants. Oecologia 1989, 78, 9-19.

38. Flexas, J.; Medrano, H. Drought-inhibition of photosynthesis in $\mathrm{C}_{3}$ plants: Stomatal and non-stomatal limitation revisited. Ann. Bot. London 2002, 89, 183-189.

39. Gordon, T.R.; Duniway, J.M. Photosynthesis in powdery mildewed sugar beet leaves. Phytopathology 1982, 72, 718-723.

40. Bainbridge, A. Effects of nitrogen nutrition of the host on barley powdery mildew. Plant Pathol. 1974, 23, 160-161.

41. Oerke, E.C.; Schönbeck, F. On the influence of abiotic stress conditions on growth of barley and bean and their predisposition for pathogens. J. Plant Dis. Protect. 1986, 93, 561-573. 
42. Lawlor, D.W. The effects of water deficit on photosynthesis. In Environment and Plant Metabolism Flexibility and Acclimation; Smirnoff, N., Ed.; BIOS Scientific Publisher: Oxford, UK, 1995; pp. 129-160.

43. Agati, G.; Mazzinghi, P.; Fusi, F.; Ambrosini, I. The F685/F730 chlorophyll fluorescence ratio as a tool in plant physiology: Response to physiological and environment factors. J. Plant Physiol. 1995, 14, 228-238.

44. Valentini, R.; Cecchi, G.; Mazzinghi, P.; Scarascia-Mugnozza, G.; Agati, G.; Bazzani, M.; De Angelis, P.; Fusi, F.; Matteucci, G.; Raimondi, V. Remote sensing of chlorophyll a fluorescence of vegetation canopies: 2. Physiological significance of fluorescence signal in response to environmental stresses. Remote Sens. Environ. 1994, 47, 29-35.

45. Peng, S.; Garcia, F.V.; Laza, R.C.; Sanico, A.L.; Visperas, R.M.; Cassman, K.G. Increased N use efficiency using a chlorophyll meter on high-yielding irrigated rice. Field Crops Res. 1996, 47, 243-252.

46. Bredemeier, C.; Schmidhalter, U. Non-contacting chlorophyll fluorescence sensing for site-specific nitrogen fertilization in wheat and maize. In Precision Agriculture; Werner, A., Stafford, J., Eds.; Wageningen Academic Publishers: Berlin, Germany, 2003; pp. 103-108.

47. Chappelle, E.; McMurtrey, J.; Wood, F.; Newcomb, W. Laser-induced fluorescence of green plants: 2. LIF caused by nutrient deficiencies in corn. Appl. Optics 1984, 23, 139-142.

48. Leuning, R.; Cromer, R.N.; Rance, S. Spatial distributions of foliar nitrogen and phosphorus in crown of Eucalyptus grandis. Oecologia 1991, 88, 504-510.

49. Pearman, I.; Thomas, S.M.; Thorne, G.N. Effects of nitrogen fertilizer on growth and yield of spring wheat. Ann. Bot. 1977, 41, 93-108.

50. Spiertz, J.H.J.; Ellen, J. Effects of nitrogen on crop development and grain growth of winter wheat in relation to assimilation and utilization of assimilates and nutrients. Neth. J. Agric. Sci. 1978, 25, 210-231.

51. Bürling, K.; Hunsche, M.; Noga, G. Use of blue-green and chlorophyll fluorescence measurements for differentiation between nitrogen deficiency and pathogen infection in winter wheat. J. Plant Physiol. 2011, 168, 1641-1648.

52. Buschmann, C.; Lichtenthaler, H.K. Principles and characteristics of multi-colour fluorescence imaging of plants. J. Plant Physiol. 1998, 152, 297-314.

53. Bagatta, M.; Pacifico, D.; Mandolino, G. Evaluation of the osmotic adjustment response within the genus Beta. J. Sugar Beet Res. 2008, 45, 119-133.

54. Chaerle, L.; Lenk, S.; Hagenbeek, D.; Buschmann, C.; Van Der Straeten, D. Multicolor fluorescence imaging for early detection of the hypersensitive reaction to tobacco mosaic virus. J. Plant Physiol. 2007, 164, 253-262.

55. Lenk, S.; Chaerle, L.; Pfündel, E.E.; Langsdorf, G.; Hagenbeek, D.; Lichtenthaler, H.K.; Van Der Straeten, D.; Buschmann, C. Multispectral fluorescence and reflectance imaging at the leaf level and its possible applications. J. Exp. Bot. 2007, 58, 807-814.

56. Nicholson, R.L.; Hammerschmidt, R. Phenolic compounds and their role in disease resistance. Annu. Rev. Phytopathol. 1992, 30, 369-389. 
57. Scholes, J.D.; Lee, P.J.; Horton, P.; Lewis, D.H. Invertase: Understanding changes in the photosynthetic and carbohydrate metabolism of barley leaves infected with powdery mildew. New Phytol. 1994, 126, 213-222.

58. Chappelle, E.W.; Wood, F.M.; McMurtrey, J.E.; Newcomb, W.W. Laser-induced fluorescence of green plants: 1. A technique for the remote detection of plant stress and species differentiation. Appl. Optics 1984, 23, 134-138.

59. Lang, M.; Lichtenthaler, H.K. Changes in the blue-green and red fluorescence emission spectra of beech leaves during the autumnal chlorophyll breakdown. J. Plant Physiol. 1991, 138, 550-553.

60. Morales, F.; Cerovic, Z.G.; Moya, I. Characterization of blue-green fluorescence in the mesophyll of sugar beet (Beta vulgaris L.) leaves affected by iron deficiency. Plant Physiol. 1994, 106, 127-133.

(C) 2014 by the authors; licensee MDPI, Basel, Switzerland. This article is an open access article distributed under the terms and conditions of the Creative Commons Attribution license (http://creativecommons.org/licenses/by/3.0/). 